\title{
Paths, pivots, and practice: the power of optimization
}

\author{
Miguel F. Anjos ${ }^{1} \cdot$ Antoine Deza ${ }^{2}$
}

Published online: 9 April 2018

(C) Springer Science+Business Media, LLC, part of Springer Nature 2018

This issue contains a selection of research articles on different topics in optimization. Most of them were presented at the conference Paths, Pivots, and Practice: The Power of Optimization that took place from 11 to 13 June, 2015, and was hosted by the Groupe d'Études et de Recherche en Analyse des Décisions (GERAD), Montréal, Québec, Canada. The conference was held in honour of Professor Tamás Terlaky on the occasion of his 60th birthday.

The articles in this issue reflect the outstanding contributions that Tamás Terlaky has made to the field of optimization. The variety of topics covered illustrates the fruitful interaction between optimization and numerous areas of computer science, engineering, and mathematics. The reader will learn new results in global optimization, nonlinear optimization, semidefinite optimization, stochastic optimization, simulation, graphs, and polytopes.

We are grateful to the authors for the high quality of their contributions, and most appreciative of the thorough reviews carried out by nearly 40 referees. We also thank Endre Boros and Katie D'Agosta for their kind help throughout the process of assembling this issue. It is our pleasure to acknowledge the organizational support of the GERAD staff, particularly Marie Perreault, Marilyne Lavoie, and Carole Dufour, as well as the nurturing environment provided by GERAD and HEC Montréal.

Antoine Deza

deza@mcmaster.ca

http://www.cas.mcmaster.ca/ deza

Miguel F. Anjos

anjos@stanfordalumni.org

http://www.miguelanjos.com

1 GERAD \& Polytechnique Montréal, Montréal, QC, Canada

2 McMaster University, Hamilton, ON, Canada 


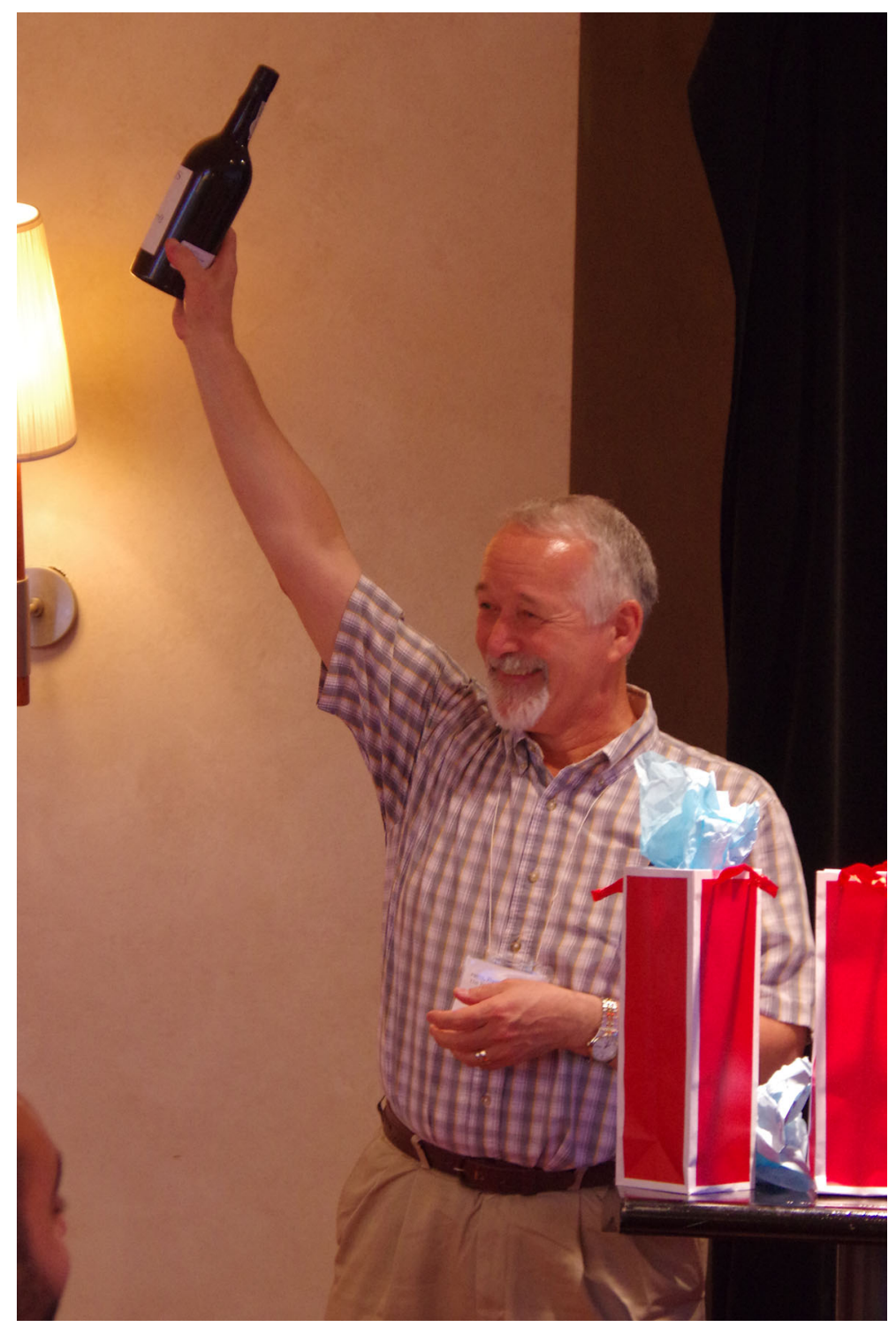

Tamás Terlaky was born in 1955 in Kaposvár, Hungary, a son of József Terlaky and Edit Kishonti. His childhood years were spent in Kaposvár. Tamás scored at the top level in several mathematics and physics competitions for high school and university students in Hungary. His early awards include the First Prize in the national KöMal contest run by the Hungarian mathematics journal for high school students in 1972/73. As a result of these successes, Tamás was admitted to Eötvös Loránd University in Budapest in 1973, where he enrolled in 1974 after a year of mandatory military service. He was awarded a Ph.D. in 1981 with Professor Emil Klafszky as his advisor, and a Candidate of Science from the Hungarian Academy of Sciences in 1985. In 2005 he was awarded the Habilitation in Information Sciences by the University of Pannonia, Veszprém, as well as the Doctor of Information Sciences by the Hungarian Academy of Sciences. 
After graduation with a combined BS/MS degree in mathematical sciences, with specialization in operations research, Tamás worked for two years at the Hungarian Oil and Gas Trust company designing production and maintenance plans. In 1981 he returned to teaching and research at Eötvös Loránd University, first at the Department of Numerical Analysis, and then as founding member of the Department of Operations Research.

After a one-year visiting position at Delft University of Technology in the Netherlands, in 1990 Tamás became a Faculty member in the Department of Statistic, Stochastic and Operations Research. In 1998, while at Delft, he founded the journal Optimization and Engineering for which he served as Editor-in-Chief until 2012. The journal's mission is to bridge the gap between optimization and engineering by promoting the advancement of optimization methods and the innovative application of optimization in engineering. Tamás continues to serve on the journal's board as Founding Editor-in-Chief.

Tamás was invited in 1999 to take up a Canada Research Chair in Optimization at McMaster University, Canada. While at McMaster he launched and led McMaster's Advanced Optimization Lab, and was the Founding Director of the School of Computational Engineering and Science. He also led one of the largest projects funded by the MITACS Network of Centres of Excellence in Canada, and initiated the Fields Institute's Industrial Optimization Seminar Series. Tamás was elected Fellow of the Fields Institute, and awarded the inaugural MITACS Mentorship Award. In the year 2000 he launched the MOPTA (Modelling, Optimization, Theory and Applications) conference series that has been held every year since then. That same year he also founded EUROPT, the Continuous Optimization Working Group of EURO, of which he is Honorary Founding Chair since 2003.

In 2008 Tamás moved to Lehigh University, U.S.A., as Chair of the Department of Industrial and Systems Engineering, as well as the holder of the George N. and Soteria Kledaras Endowed Chair. As Chair at Lehigh University, he remarkably boosted the department on all key levels: enrolment, hiring, funding, curriculum, visibility, and research output. Tamás is a highly inspirational and skilled motivator. Recognitions of his successes as department chair include being four times finalist for the UPS George D. Smith Prize of INFORMS.

Tamás has served the optimization community in numerous ways: as Chair of the INFORMS Optimization Society, Chair of the ICCOPT Steering Committee of the Mathematical Programming Society, Chair of the SIAM Activity Group on Optimization, General Chair of the 2015 INFORMS Annual Meeting in Philadelphia, and as a member of many award committees, conference organizations, and program committees, additionally he serves on more than ten journal and book series editorial boards. Elected Fellow of INFORMS in 2016, he is the recipient of the prestigious INFORMS Wagner Prize in 2017. That same year he received the Egerváry Memorial Award by the Hungarian Operations Research Society.

Tamás's research interests are in high performance optimization methods, optimization modelling, and optimization problems in the engineering sciences. He is the author of more than 200 research papers, many of which are highly cited. He wrote the seminal books Interior Point Approach to Linear Optimization: Theory and Algorithms (with Kees Roos and JeanPhilippe Vial) and Self-Regularity: A New Paradigm for Primal-Dual Interior Point Methods (with Jiming Peng and Kees Roos). These two monographs bring the reader to the frontiers of research in interior point methods.

Tamás has always been interested in teaching, which he finds very rewarding. He has graduated more than $20 \mathrm{Ph} . \mathrm{D}$. students, and supervised more than 12 postdoctoral fellows. His former students are professors in Hungary, the Netherlands, Belgium, Iran, Canada, and the USA, and senior researchers work at leading companies such as IBM, SAS, Capital One, and JP Morgan. 
Tamás's work and career were influenced by a number of great colleagues and friends, including Emil Klafszky, Komei Fukuda, Kees Roos, Jean-Philippe Vial, Michael J. Todd, and Henry Wolkowicz. He has always enjoyed travelling, often accompanied by his lovely wife Gabriella. Their son Viktor earned a Ph.D. in sedimental geology from the University of Ottawa, and works as Senior Geologist for the Geological Survey of the Northwest Territories of Canada.

We are delighted to dedicate this issue to our friend and mentor, in recognition of his highly successful career and his important contributions to the field of mathematical optimization. 